\title{
Development of novel antibacterial active, HaCaT biocompatible and biodegradable CA-g-P(3HB)-EC biocomposites with caffeic acid as a functional entity
}

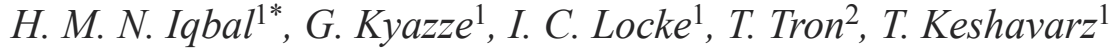 \\ ${ }^{1}$ Applied Biotechnology Research Group, Department of Life Sciences, Faculty of Science and Technology, University of \\ Westminster, W1W 6UW London, United Kingdom \\ ${ }^{2}$ Aix Marseille Université, CNRS, Centrale Marseille, iSm2 UMR 7313, 13397 Marseille, France
}

Received 1 January 2015; accepted in revised form 26 March 2015

\begin{abstract}
We have developed novel composites by grafting caffeic acid (CA) onto the $\mathrm{P}(3 \mathrm{HB})$-EC based material and laccase from Trametes versicolor was used for grafting purposes. The resulting composites were designated as $\mathrm{CA}-g-\mathrm{P}(3 \mathrm{HB})-$ EC i.e., $\mathrm{P}(3 \mathrm{HB})-\mathrm{EC}$ (control), 5CA-g-P(3HB)-EC, 10CA-g-P(3HB)-EC, 15CA-g-P(3HB)-EC and 20CA-g-P(3HB)-EC. FT-IR (Fourier-transform infrared spectroscopy) was used to examine the functional and elemental groups of the control and laccase-assisted graft composites. Evidently, 15CA-g-P(3HB)-EC composite exhibited resilient antibacterial activity against Gram-positive and Gram-negative bacterial strains. Moreover, a significant level of biocompatibility and biodegradability of the CA-g-P(3HB)-EC composites was also achieved with the human keratinocytes-like HaCaT cells and soil burial evaluation, respectively. In conclusion, the newly developed novel composites with multi characteristics could well represent the new wave of biomaterials for medical applications, and more specifically have promising future in the infection free would dressings, burn and/or skin regeneration field due to their sophisticated characteristics.
\end{abstract}

Keywords: polymer composites, enzymatic grafting, laccase, biocompatible, biodegradable

\section{Introduction}

Bio-polymers generated from natural sources are non-toxic in nature and therefore should be extraordinarily suitable for biomedical applications such as tissue engineering. Among the most promising and well-characterised bio-polymers of natural origin, $\mathrm{P}(3 \mathrm{HB})$ and cellulose are of particular interest to prepare composites with novel functionalities $[1,2]$. Depending on the physiochemical nature and compatibility of the individual constituent surfaces, either $\mathrm{P}(3 \mathrm{HB})$ or cellulose, various interactions can occur at the interface. Interfacial chemical reactions can lead to various intermolecular bonds such as hydrogen bonding type interactions. Surface functionalities of $\mathrm{P}(3 \mathrm{HB})$ and cellulose include moderately polar
$(>\mathrm{C}=\mathrm{O})$ and polar groups $(-\mathrm{OH}$ and $-\mathrm{COOH})$ and one primary and two secondary hydroxyl groups, respectively which possibly interact, and generate some new bonds during composite formation [3, 4]. In recent years, a great interest has grown in the development of polymeric materials or composites with multifunctional characteristics, such as antibacterial, anticorrosive, biocompatible and biodegradable, to explore their potential for wider use in a variety of applications e.g. biomedical, pharmaceutical, drug delivery, food packaging, sanitary materials, household, energy and military items [2, 4-8]. In our previous work, novel enzyme-based composites by grafting poly(3-hydroxybutyrate) $[\mathrm{P}(3 \mathrm{HB})]$ onto the ethyl cellulose (EC) and bacterial cellulose (BC) as

\footnotetext{
${ }^{*}$ Corresponding author, e-mail: hafiz.iqbal@my.westminster.ac.uk (C) BME-PT
} 
a backbone polymers were developed under mild and eco-friendly environment and analysed the improved thermo-mechanical properties conferred to the biomaterials based composites obtained $[2,4,7]$. From the last few years, antimicrobial finishing of medical materials has become extremely important in the production of protective, biocompatible, biodegradable, non-toxic products with respect to the health and safety. This has provided opportunities to expand the use of biomaterials to different applications in the pharmaceutical, medical, tissue engineering, agricultural, and food industries [4-7]. Most phenols like caffeic acid, as natural auxiliaries host antimicrobial activity and can also be grafted to improve or impart existing or antimicrobial properties, respectively. The cross-linking of some of the natural phenolic compounds to different polymers is evidenced after an enzymatic stage with $P$. cinnabarinus laccase $[9,10]$. Laccase catalyses the oxidation of aromatic compounds using molecular oxygen as electron acceptor thus has been successfully applied for grafting of phenolic compounds on different natural polymers. In the last decade several authors have shown that laccase treatments can improve physical/ chemical properties by producing phenoxy radicals that undergo cross-linking reactions [11-13], thus enhancing and/or imparting completely new properties to the materials, for a better performance, or to create new value-added products. The recent years have also witnessed a revival of the interest for natural materials capable of controlling microbial contaminations due to their fewer side effects and nontoxicity $[14,15]$. Thus they hold a great potential and represent a valuable alternative and new challenges for the future to keep under control microbial contamination.

In this work, we have developed novel CA-g$\mathrm{P}(3 \mathrm{HB})$-EC composites, which exert strong antibacterial activities. The improved resistance against a wide spectrum of microbes as well as the $\mathrm{HaCaT}$ compatibility and biodegradability all indicate that the newly synthesised CA- $g$-P(3HB)-EC based novel composites could be potential candidate biomaterials for medical applications, and more specifically have promising future in the infection free wound dressings, burn and/or skin regeneration field due to their sophisticated characteristics.

\section{Experimental section}

\subsection{Bacterial cultures and maintenance}

The pure cultures of the Gram-positive bacteria i.e., Bacillus subtilis NCTC 3610 and Staphylococcus aureus NCTC 6571 and the Gram-negative i.e., Escherichia coli NTCT 10418 and Pseudomonas aeruginosa NCTC 10662 were obtained from the culture collection unit of the University of Westminster London, UK. All of the collected strains were streaked on nutrient agar plates and subsequently used for inoculum development. Each strain, separately, was grown overnight in $50 \mathrm{~mL}$ sterile nutrient broth at $30^{\circ} \mathrm{C}$ and $120 \mathrm{rpm}$. The main constituents of the broth were: $1.0 \mathrm{~g} / \mathrm{L}$; yeast extract, $2.0 \mathrm{~g} / \mathrm{L}$; peptone, $5.0 \mathrm{~g} / \mathrm{L}$; sodium chloride, $5.0 \mathrm{~g} / \mathrm{L}$.

\subsection{Production and extraction of $\mathbf{P}(3 \mathrm{HB})$}

The Gram-positive B. subtilis NCTC 3610 was used for the production of $\mathrm{P}(3 \mathrm{HB})$ using a modified $\mathrm{G}$ medium (MGM) [16]. After the stipulated fermentation time period $(72 \mathrm{~h}),(\mathrm{P} 3 \mathrm{HB})$ was extracted from the cells using the chloroform-hypochlorite dispersion method [17]. Isolated $\mathrm{P}(3 \mathrm{HB})$ was then stored in air tight desiccated jars to keep moisture free and used further in subsequent graft synthesis experiments.

\subsection{Grafting of $\mathrm{CA}$ onto the $\mathrm{P}(3 \mathrm{HB})-\mathrm{EC}$}

The grafting of CA onto the as-reported $\mathrm{P}(3 \mathrm{HB})$-EC based composite [2], was performed by adopting surface dipping and incorporation (SDI) technique. Briefly, the pre-weight $\mathrm{P}(3 \mathrm{HB})-\mathrm{EC}$ composite was dipped into the CA solution in the presence of laccase for $60 \mathrm{~min}$ at $30^{\circ} \mathrm{C}$. After that weight of the com-

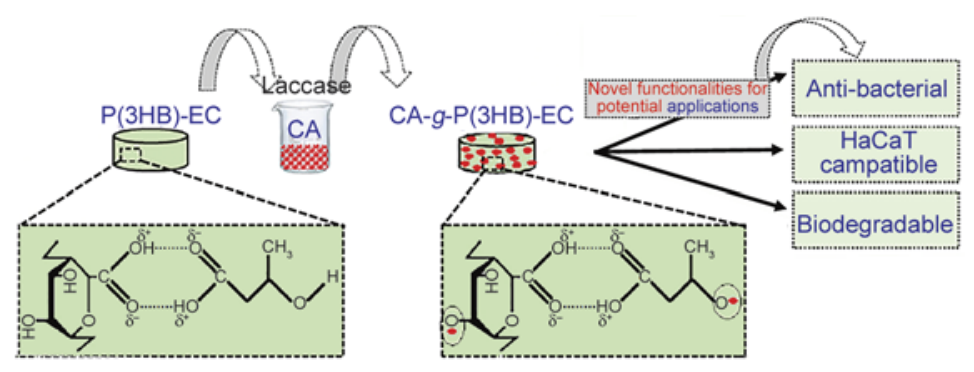

Figure 1. Schematic representation of preparation and evaluation of CA-g-P(3HB)-EC composites 
posite was recorded in a swollen state followed by incubation at $50^{\circ} \mathrm{C}$ until fully dried. To eliminate the un-reacted $\mathrm{CA}$ monomers each composite was washed three times using sodium malonate buffer and then dried again at $50^{\circ} \mathrm{C}$ and final dry weight was recorded to calculate the grafting parameters. Subsequently, the resulting composites were designated as $\mathrm{P}(3 \mathrm{HB})-\mathrm{EC}$, 5CA-g-P(3HB)-EC, 10CA- $g$-P(3HB)EC, 15CA- $g-\mathrm{P}(3 \mathrm{HB})-\mathrm{EC}$ and 20CA-g-P(3HB)-EC. $A$ possible mechanism of action between $C A$ and $\mathrm{P}(3 \mathrm{HB})$-EC composite is shown in Figure 1.

\subsection{Fourier transform infrared spectroscopy (FT-IR)}

A Perkin Elmer System 2000 FT-IR spectrophotometer was used to identify the structural elements of the individual CA, $\mathrm{P}(3 \mathrm{HB})-\mathrm{EC}$ and $\mathrm{CA}-\mathrm{g}-\mathrm{P}(3 \mathrm{HB})-$ $\mathrm{EC}$ composites. The individual polymers and grafted composites were placed on the diamond crystal, and infrared absorption spectra were recorded from the wavelength region of $4000-500 \mathrm{~cm}^{-1}$. All spectra were collected with 64 scans and $2 \mathrm{~cm}^{-1}$ resolution and assigned peak numbers.

\subsection{Grafting parameters}

The grafting parameters i.e., graft yield $(G Y \%)$, grafting efficiency $(G E \%)$ and swelling ratio $(S R \%)$ were measured. Graft yield was calculated in percentage by Equation (1), grafting efficiency was calculated in percentage by Equation (2) and swelling ratio was calculated in percentage by Equation (3):

$$
\text { Graft yield } \quad(G Y \%)=\frac{W_{\mathrm{f}}-W_{\mathrm{i}}}{W_{\mathrm{i}}} \times 100
$$

Grafting efficiency $(G E \%)=\frac{W_{\mathrm{f}}-W_{\mathrm{i}}}{W_{\mathrm{s}}-W_{\mathrm{i}}} \times 100$

Swelling ratio

$$
(S R \%)=\frac{W_{\mathrm{s}}-W_{\mathrm{i}}}{W_{\mathrm{i}}} \times 100
$$

where, $W_{\mathrm{i}}=$ initial weight before immersion; $W_{\mathrm{f}}=$ final dry weight after immersion; and $W_{\mathrm{s}}=$ weight of a sample in the swollen state.

\subsection{Testing antibacterial activity}

The antibacterial activities of the $\mathrm{P}(3 \mathrm{HB})-\mathrm{EC}$ and CA-g-P(3HB)-EC composites were tested against the aforementioned Gram-positive and Gram-negative strains. An overnight grown spore suspensions containing approximately $10^{5} \mathrm{CFU} / \mathrm{mL}$ were inocu- lated onto the sterilised surfaces of the $\mathrm{P}(3 \mathrm{HB})$-EC and $\mathrm{CA}-\mathrm{g}-\mathrm{P}(3 \mathrm{HB})-\mathrm{EC}$ composites followed by incubation at $30^{\circ} \mathrm{C}$. After the stipulated incubation period (24 h), the bacterial cells were washed twice using $50 \mathrm{~mL}$ of phosphate buffer. The CFU/mL in each of the washed suspension was determined by conventional spread-plate method. In comparison with control (initial bacterial count) the $\mathrm{CFU} / \mathrm{mL}$ values were used to calculate the antibacterial efficacy of the $\mathrm{P}(3 \mathrm{HB})-\mathrm{EC}$ and $\mathrm{CA}-\mathrm{g}-\mathrm{P}(3 \mathrm{HB})-\mathrm{EC}$ composites by Equation (4):

\section{Log reduction $=$ \\ Log CFU control - Log CFU treated sample \\ 2.7. In-vitro cell viability and adherent morphology}

$\mathrm{HaCaT}$ cell line was adopted to evaluate the cytotoxicity of the $\mathrm{P}(3 \mathrm{HB})$-EC and CA-g-P(3HB)-EC composites. HaCaT cells at a density of $1 \times 10^{5}$ cells per well were seeded in 24-well tissue culture plates containing $\mathrm{P}(3 \mathrm{HB})-\mathrm{EC}$ and $\mathrm{CA}-\mathrm{g}-\mathrm{P}(3 \mathrm{HB})-\mathrm{EC}$ composites separately. After 1, 3 and 5 days of incubation the culture media were removed and the specimens were rinsed with phosphate buffer saline three times in order to remove the un-attached cells. Cell viability of the adherent cells was measured using neutral red uptake assay. Thermomax micro-plate reader (Model 680 , Bio-Rad, CA) was used to record optical density values at $540 \mathrm{~nm}$ using Softmax Pro version 4.8 software. Percent cell viability of the test specimens was calculated by Equation (5). Whereas, the adherent morphology of $\mathrm{HaCaT}$ cell line seeded onto the $\mathrm{P}(3 \mathrm{HB})-\mathrm{EC}$ and CA-g-P(3HB)-EC composites was observed using Nikon light microscope after staining with neutral red dye. After $1 \mathrm{~h}$ incubation in dye solution, the stained cells were first washed with PBS and then images were recorded at $100 \times$ magnification.

$$
\begin{aligned}
& \% \text { Cell viability }= \\
& \frac{O D_{\text {Test composite }}-O D_{\text {Negative control }}}{O D_{\text {Positive control }}}
\end{aligned}
$$

\subsection{Soil burial test}

The biodegradability of the $\mathrm{P}(3 \mathrm{HB})-\mathrm{EC}$ and CA-g$\mathrm{P}(3 \mathrm{HB})-\mathrm{EC}$ composites was evaluated using soil burial test as-described earlier by Wattanakornsiri et al. [18]. The soil burial test lasted for 6 weeks (42 days). 
A set of triplicate samples were buried under the soil surface and after every 7 days of burial, each set was removed, washed with distilled water, dried under ambient environment and loss in weight was recorded. The weight loss was calculated in percentage by Equation (6):

$\%$ Loss in weight $=$

$$
\frac{\text { Control weight }- \text { Loss in weight }}{\text { Control weight }}
$$

\section{Results and discussion}

\subsection{Fourier transform infrared spectroscopy (FT-IR)}

An FT-IR was used to examine the functional and elemental groups of CA and $\mathrm{P}(3 \mathrm{HB})-\mathrm{EC}$ and their laccase-assisted graft composites i.e., 5CA-g-P(3HB)EC, 10CA-g-P(3HB)-EC, 15CA-g-P(3HB)-EC and 20CA-g-P(3HB)-EC. In comparison to the untreated caffeic acid as shown in Figure 2, an increase in the absorbance at $1720 \mathrm{~cm}^{-1}(\mathrm{C}=\mathrm{O})$ band, and 1050 $1300 \mathrm{~cm}^{-1}(\mathrm{C}-\mathrm{O})$ was noticed. The $-\mathrm{OH}$ bands overlapped in the $3400 \mathrm{~cm}^{-1}$ region, whereas, the peaks at $3396 \mathrm{~cm}^{-1}$ and in a broad $3100-3470 \mathrm{~cm}^{-1}$ region can be attributed to -OH, stretch [19, 20]. In Figure 2, CA-loaded composites shows a band at $3345 \mathrm{~cm}^{-1}$ corresponding to phenolic - $\mathrm{OH}$ stretching involving hydrogen bonding, and a peak at $1360 \mathrm{~cm}^{-1}$ corresponds to $-\mathrm{OH}$ bending of the phenolic group [21].

\subsection{Grafting parameters}

The results obtained are illustrated as mean values of three replicates in Figure 3, whereas, the standard error of means are shown as Y-error bars in Figure 3. The data revealed the increase in both the graft yield $(G Y \%)$ and graft efficiency $(G E \%)$ reaching its maximum value at $15 \mathrm{mM}$ CA concentration, then starts to decrease showing that higher concentrations do not promote further grafting. One possible reason for the observed behaviour could be the substantial amount of CA grafted onto the baseline composite, which creates steric hindrance for further grafting. The increase in monomer concentration would be expected to increase both the grafting percentage which in turn increase the molecular weight of the graft composite [22, 23]. The order of $S R \%$ observed was: 20CA-g-P(3HB)-EC > 15CA- $g$-P(3HB)-EC $>$

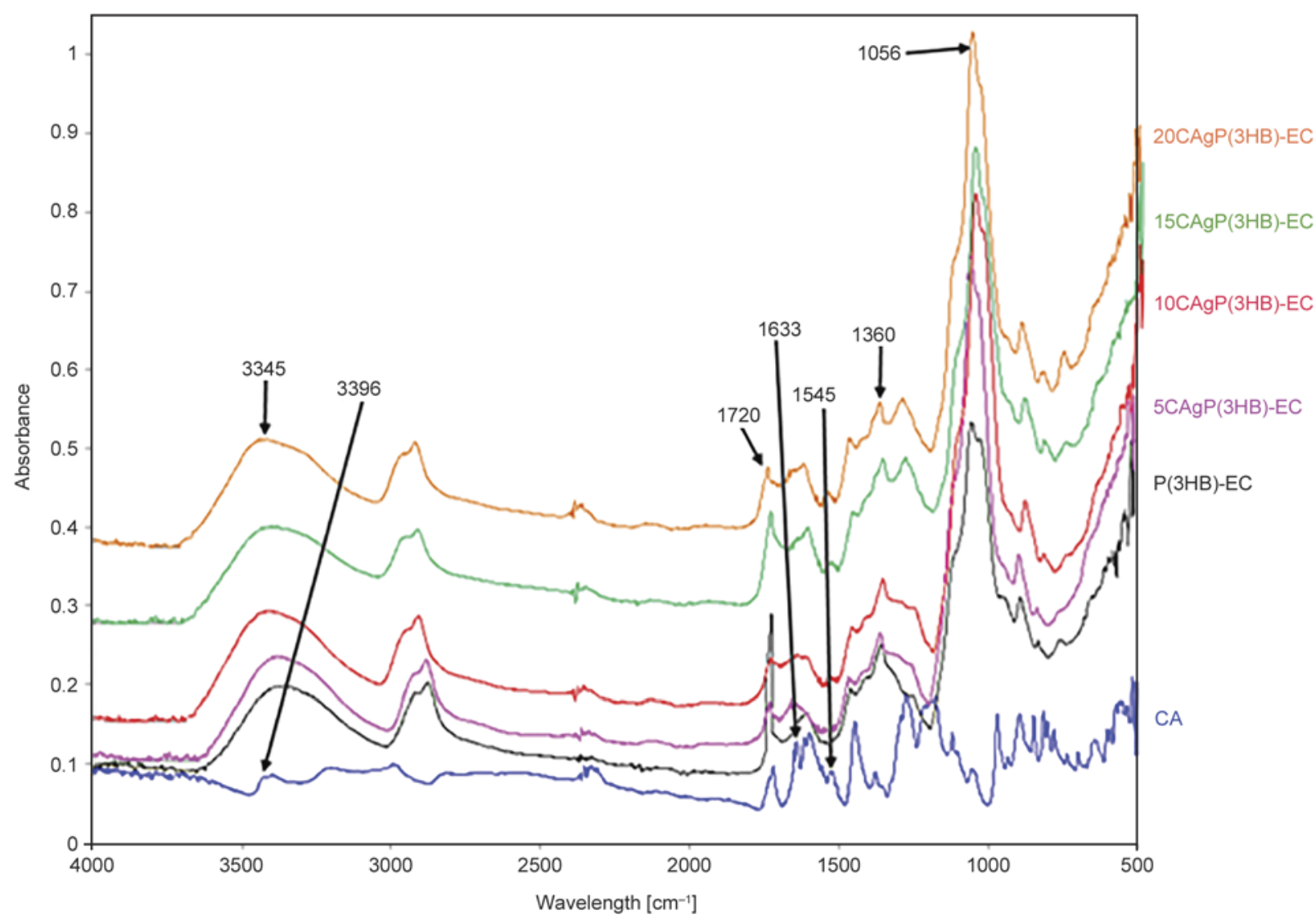

Figure 2. Typical FT-IR spectra of caffeic acid (CA) and CA-g-P(3HB)-EC composites prepared using laccase as a model catalyst 


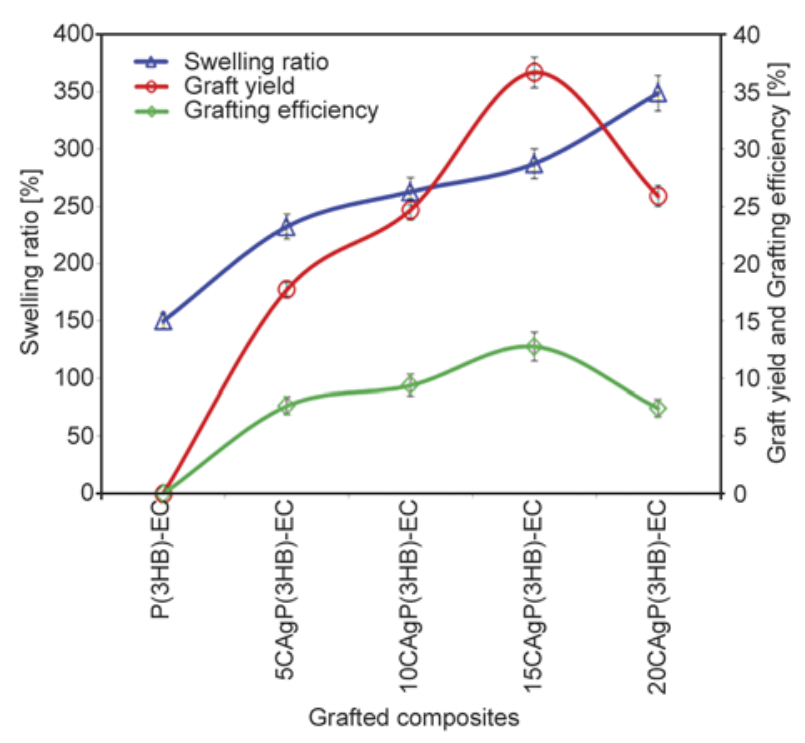

Figure 3. Graft yield ( $G Y \%)$, grafting efficiency $(G E \%)$ and swelling ratio $(S R \%)$ behaviours of $\mathrm{CA}-g-\mathrm{P}(3 \mathrm{HB})$ EC composites prepared using laccase as a model catalyst

10CA- $g$-P(3HB)-EC $>5 \mathrm{CA}-g$-P(3HB)-EC $>\mathrm{P}(3 \mathrm{HB})-$ $\mathrm{EC}$. It has also been reported in literature that the reaction time is an important parameter which can increase or decrease the grafting parameters like graft yield, grafting efficiency and swelling behaviour [24].

\subsection{Testing antibacterial activity}

The antibacterial potential of CA-g-P(3HB)-EC composites was tested against Gram-positive and

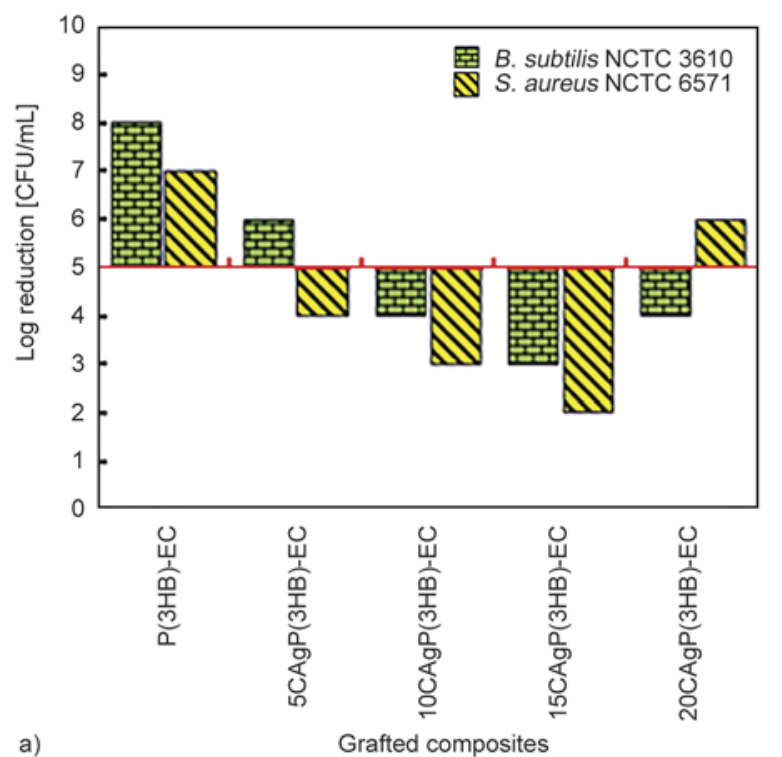

Gram-negative strains. As shown in Figure 4a and $4 \mathrm{~b}$, after $24 \mathrm{~h}$ incubation the remaining bacterial counts decreased with increasing $\mathrm{CA}$ content onto the surface of $\mathrm{P}(3 \mathrm{HB})-\mathrm{EC}$, and this trend was maximum at the concentration of $15 \mathrm{mM} \mathrm{CA}$. A significant antibacterial potential was detected for 15CA-g$\mathrm{P}$ (3HB)-EC against Gram-positive strains i.e., B. subtilis NCTC 3610 and S. aureus NCTC 6571 and the Gram-negative i.e., E. coli NTCT 10418 and $P$. aeruginosa NCTC 10662 in comparison to the control sample and relative to other concentrations. However, $\mathrm{P}(3 \mathrm{HB})-\mathrm{EC}$ without any CA concentration was found $100 \%$ susceptible against all of the tested micro-organisms. A strong antibacterial potential of $15 \mathrm{CA}-\mathrm{g}-\mathrm{P}(3 \mathrm{HB})-\mathrm{EC}$ was recorded against Gram-negative as compare to the Gram-positive, which is, probably because of the difference between Gram-negative and Gram-positive bacteria in terms of cell structures and antimicrobial mechanism [25, 26].

\subsection{In-vitro cell viability and adherent morphology}

In-vitro biocompatibility evaluation of the grafted composites with HaCaT cell line was analysed using neutral red dye assay and the results obtained are shown in Figure 5. The study demonstrated that when HaCaT cells were seeded onto the composite surfaces after $30 \mathrm{~min}$ UV sterilisation, the cells showed high viability after 5 days of incubation, whereas, the

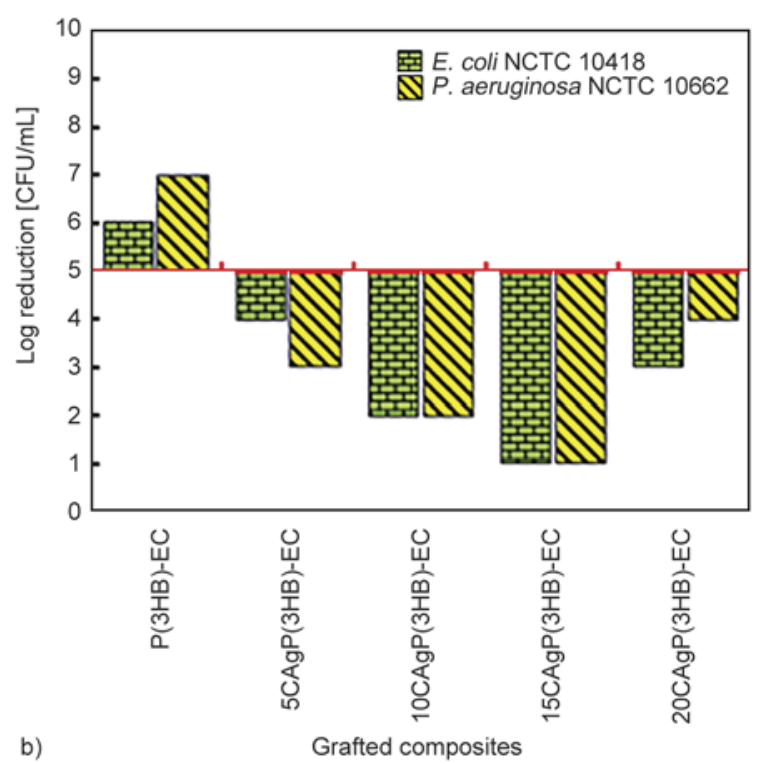

Figure 4. Antimicrobial activity of CA-g-P(3HB)-EC composites (a) against Gram-positive strains i.e., B. subtilis NCTC 3610 and S. aureus NCTC 6571 and (b) against Gram-negative strains i.e., E. coli NTCT 10418 and P. aeruginosa NCTC 10662 


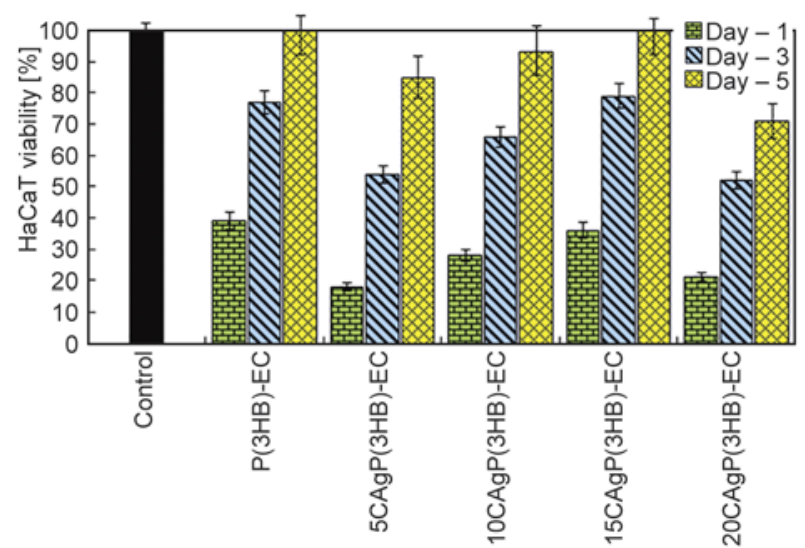

Figure 5. Neutral red dye concentration dependent percentage cell viability of human keratinocytes-like HaCaT cells after 1, 3 and 5 days of incubation onto the CA- $g-\mathrm{P}(3 \mathrm{HB})$-EC composite surfaces (mean $\pm \mathrm{SD}, n=3$ )

non-toxicity of test samples i.e., $\mathrm{P}(3 \mathrm{HB})-\mathrm{EC}, 5 \mathrm{CA}-g$ $\mathrm{P}(3 \mathrm{HB})-\mathrm{EC}, 10 \mathrm{CA}-\mathrm{g}-\mathrm{P}(3 \mathrm{HB})-\mathrm{EC}, 15 \mathrm{CA}-g-\mathrm{P}(3 \mathrm{HB})-$ $\mathrm{EC}$ and 20CA-g-P(3HB)-EC were depicted by the $\%$ viability of the $\mathrm{HaCaT}$ cells. However, the composite prepared with $20 \mathrm{mMCA}$ concentration and designated as 20CA- $g$-P(3HB)-EC showed a lower \% viability of $\mathrm{HaCaT}$ cells in comparison with the control and 15CA-g-P(3HB)-EC composites after a long contact period (5 days) under the same culturing environment. Additionally, the morphologies of cell cultured on the sterilised surface of $15 \mathrm{CA}-g$ $\mathrm{P}(3 \mathrm{HB})-\mathrm{EC}$ composite was higher than those of 20CA-g-P(3HB)-EC composite (Figure 6), which is again consistent with the results from viability analyses.

\subsection{Biodegradability evaluation}

The degradation behaviour of $\mathrm{P}(3 \mathrm{HB})-\mathrm{EC}$ and $\mathrm{CA}$ grafted $\mathrm{P}(3 \mathrm{HB})$-EC composites has been investigated by measuring the $\%$ weight loss of the composites. Figure 7 illustrates the $\%$ weight loss of the test composites as a function of degradation time, as represented, all of the composites show an increased degradation rate up to different extent during the buried process which is much likely a result of the moisture (water) penetration into the composites, causing the hydrolysis of surfaces and interfaces [27, 28]. After 6 weeks consecutive exposure, the weight loss of composites reaches $54 \mathrm{wt} \%$ for the pristine $\mathrm{P}(3 \mathrm{HB})-\mathrm{EC}, 65 \mathrm{wt} \%$ for $5 \mathrm{CA}-\mathrm{g}-\mathrm{P}(3 \mathrm{HB})-\mathrm{EC}, 81 \mathrm{wt} \%$ for $10 \mathrm{CA}-g-\mathrm{P}(3 \mathrm{HB})-\mathrm{EC}, 89 \mathrm{wt} \%$ for $15 \mathrm{CA}-g-$ $\mathrm{P}(3 \mathrm{HB})-\mathrm{EC}$ and $96 \mathrm{wt} \%$ for 20CA-g-P(3HB)-EC.

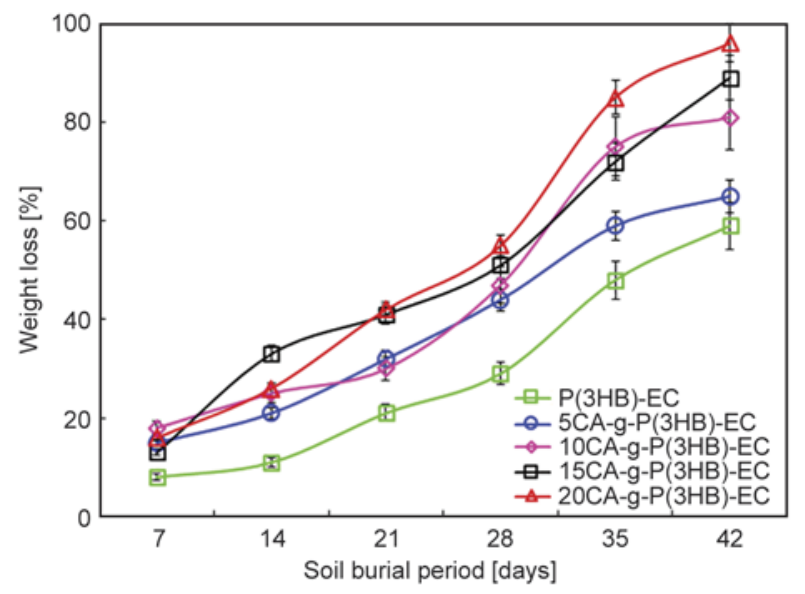

Figure 7. Percentage weight loss of CA-g-P(3HB)-EC composites buried for prescribed periods (mean $\pm \mathrm{SD}$, $n=3$ )

The degradation profile revealed that the degradability of the CA grafted composites is higher than that of bare $\mathrm{P}(3 \mathrm{HB})$-EC. It has been reported in literature that during soil burial the polymer molecular chains degrade which followed by their transformation into water and $\mathrm{CO}_{2}$ after a long term degradation, thus, it seems that the soil burial degradation mechanism involves a recyclable, green, and environmentally friendly process to fully degrade the biodegradable polymeric composites [29].

\section{Conclusions}

It could be concluded from the data discussed above, the newly developed novel composites could well represent the new wave of biomaterials for medical application, to be used to treat specific infections rather than the broad spectrum which can cause significant morbidity as a consequence of their lack of specificity. The improved resistance against a wide spectrum of microbes as well as $\mathrm{HaCaT}$ compatibility all indicates that CA-g-P(3HB)-EC could be potential candidates for biomedical applications particularly in the area of infection free wound healing. Undoubtedly, the results obtained, herein, after soil burial degradation revealed that $\mathrm{CA}-g-\mathrm{P}(3 \mathrm{HB})-\mathrm{EC}$ composites will not cause any deleterious ecological impact.

\section{Acknowledgements}

The authors thankfully acknowledge the financial support and laboratory facilities from the University of Westminster under Cavendish Research Scholarship program. 

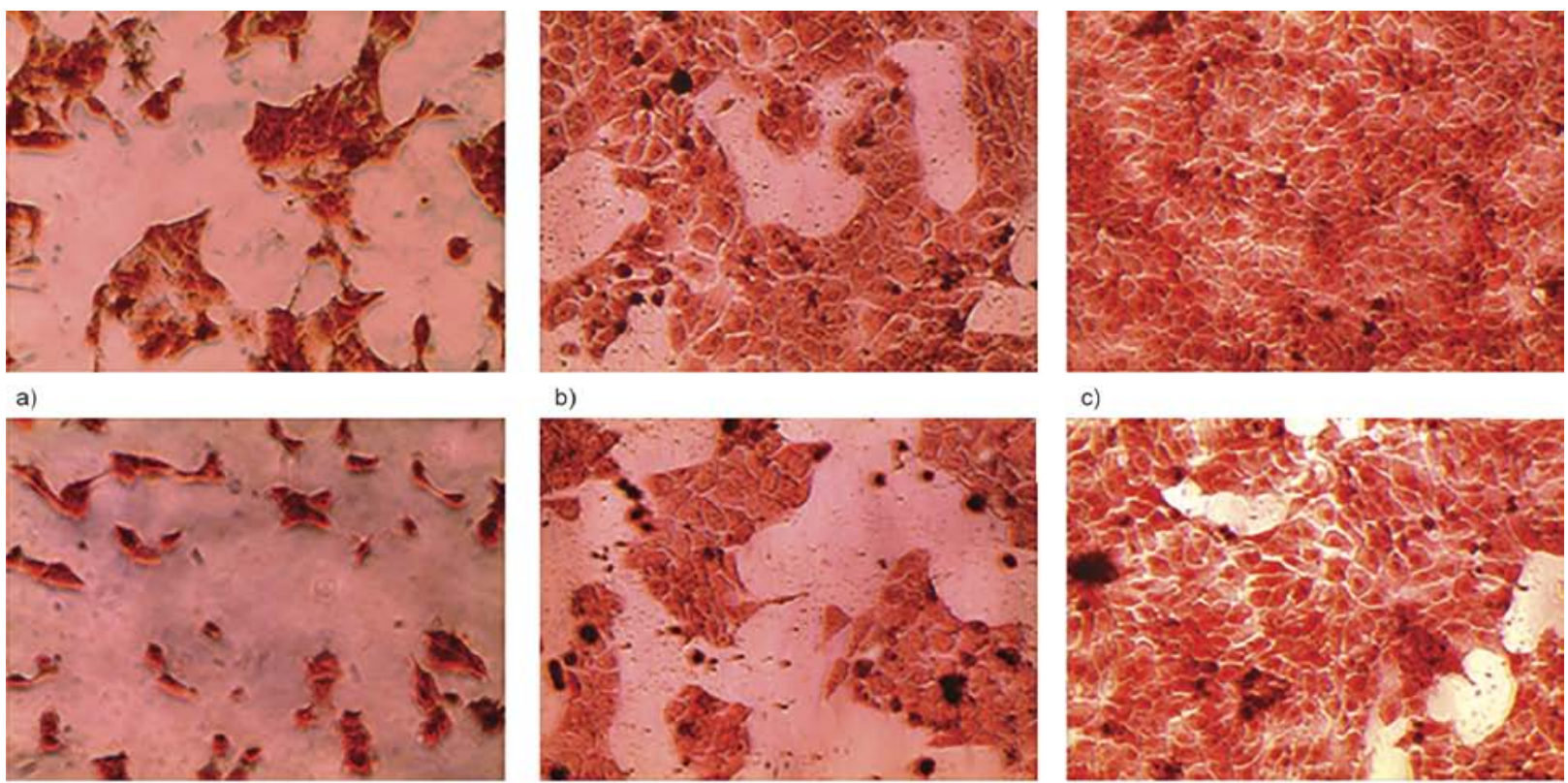

d)

b)

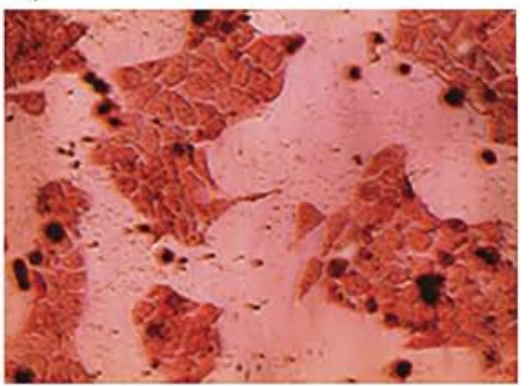

e)
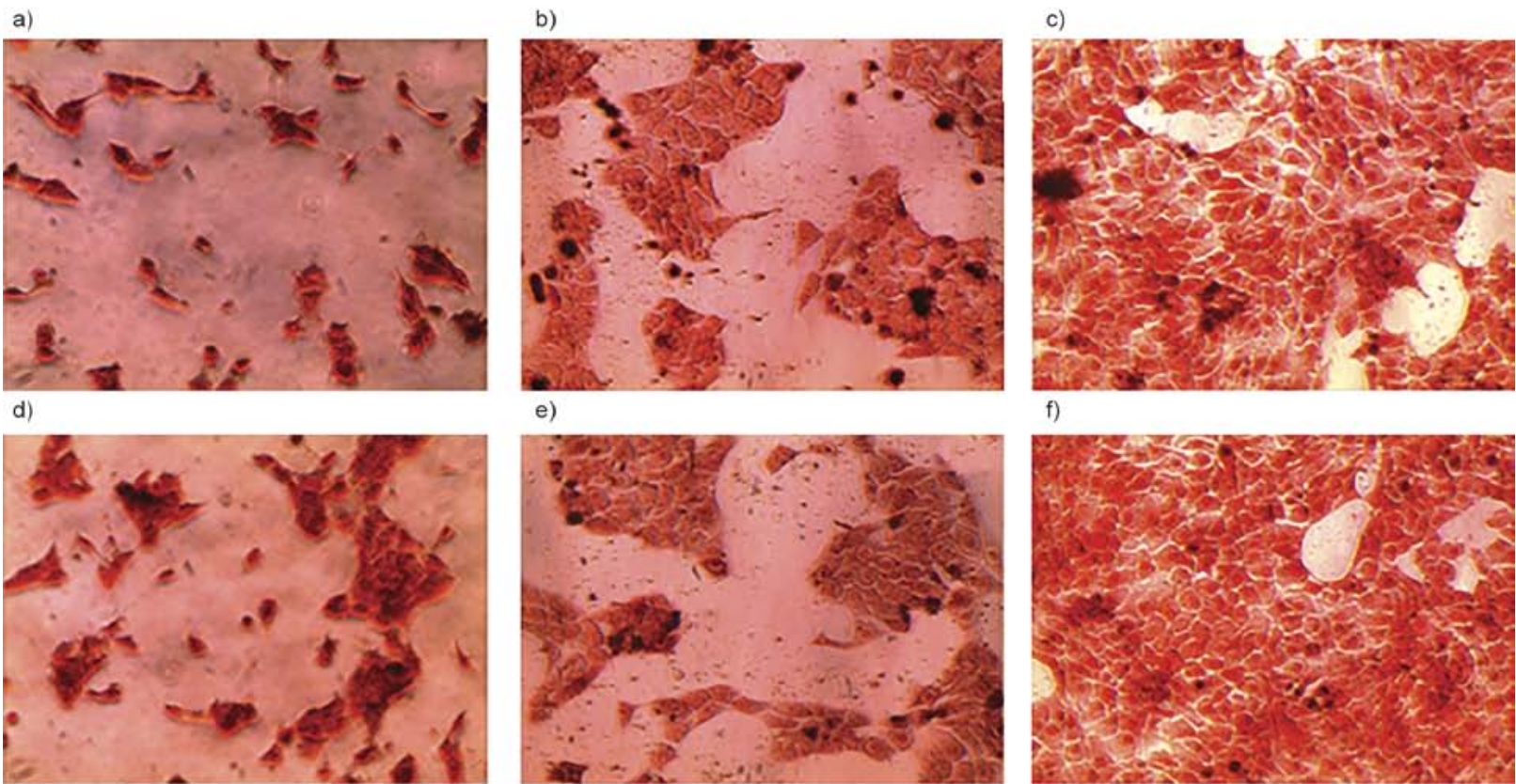

g)

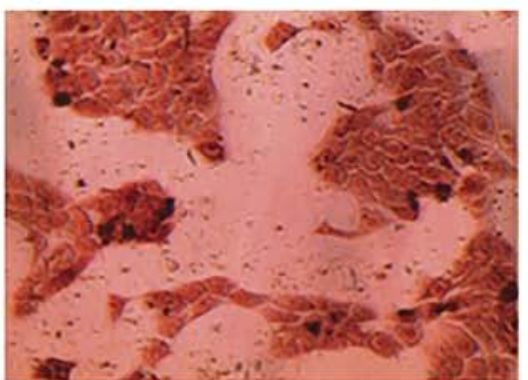

h)
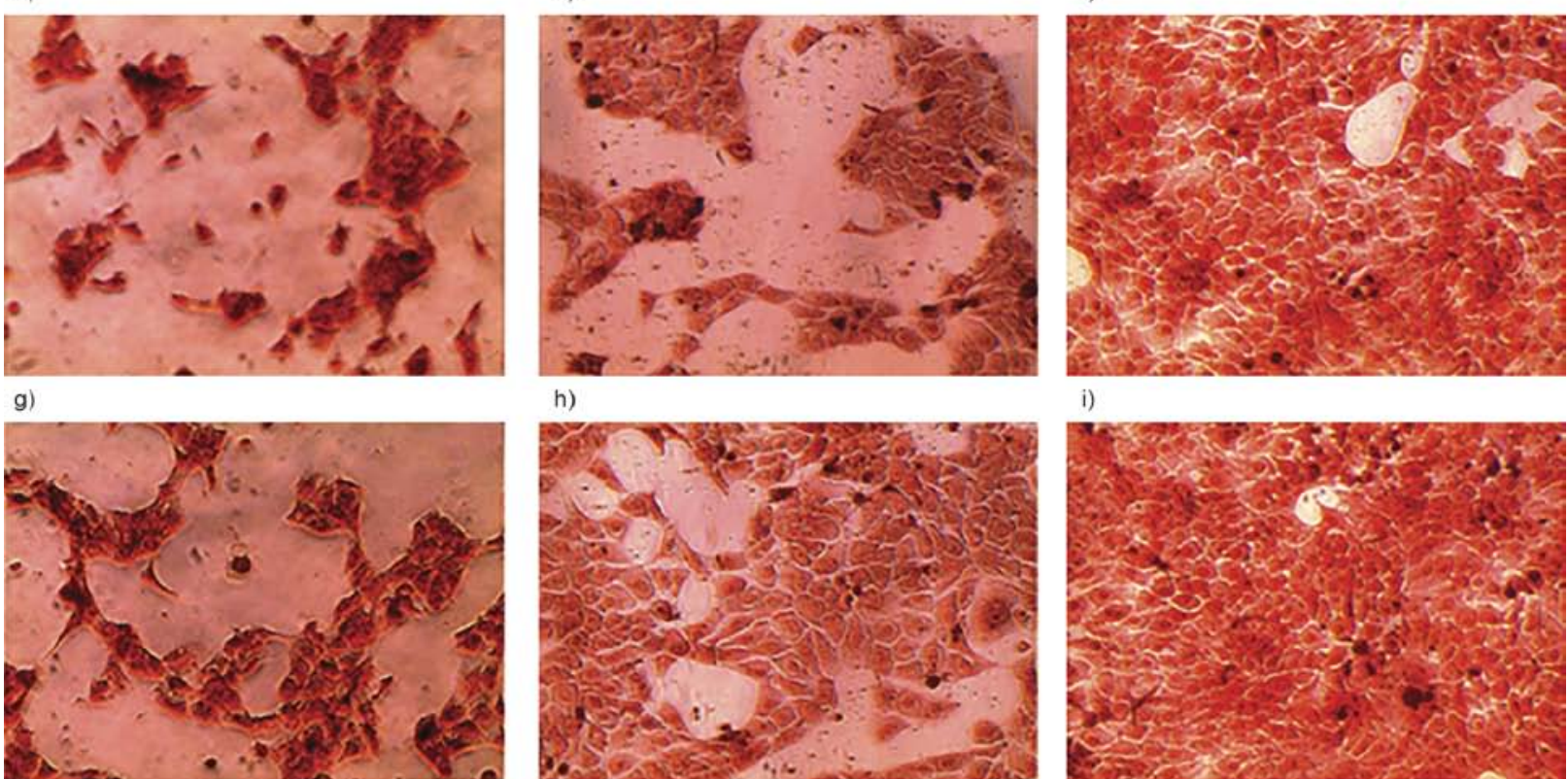

j)

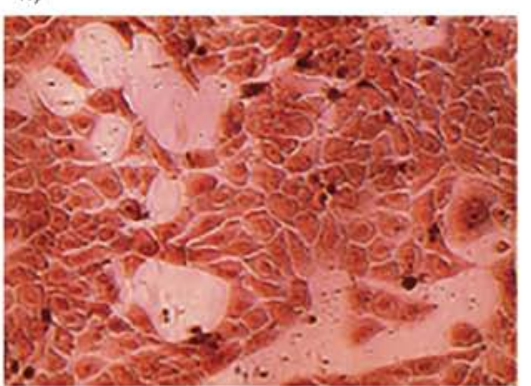

k)

i)

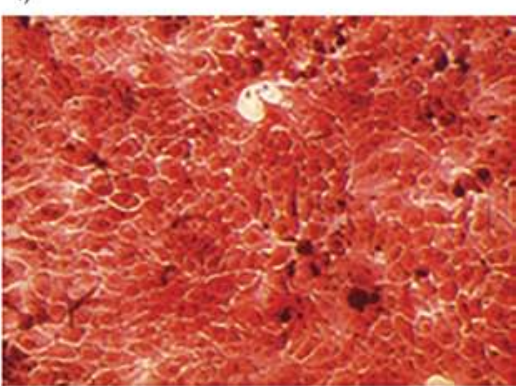

I)

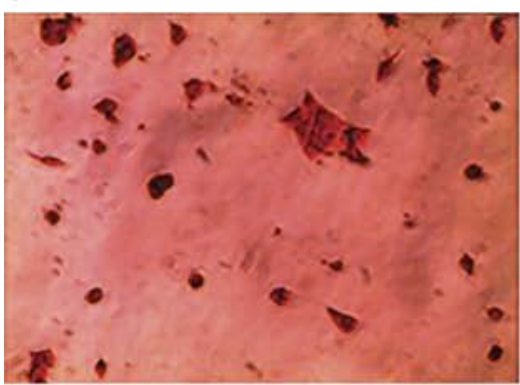

m)

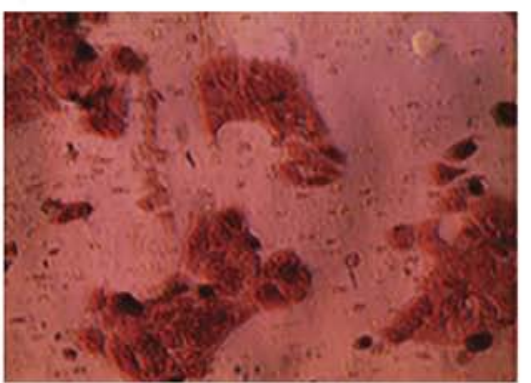

n)

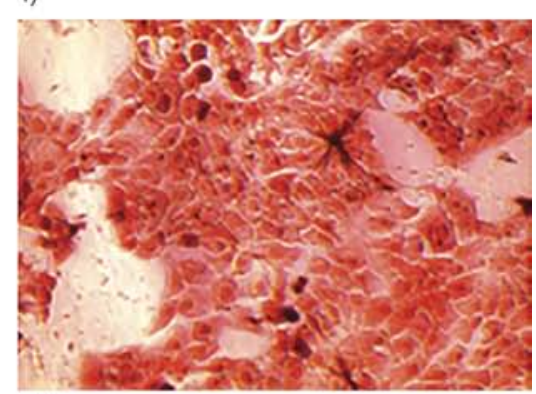

o)

Figure 6. Adherent morphology of HaCaT cells seeded onto the composite surfaces. Images (a), (b) and (c) represent the HaCaT cells on native $\mathrm{P}(3 \mathrm{HB})$-EC composite (i.e., $\mathrm{P}(3 \mathrm{HB})-\mathrm{EC})$ after 1, 3 and 5 days of incubation, respectively; images (d), (e) and (f) represent the HaCaT cells on 5CA-g-P(3HB)-EC composite after 1, 3 and 5 days of incubation, respectively; images (g), (h) and (i) represent the HaCaT cells on 10CA-g-P(3HB)-EC composite after 1, 3 and 5 days of incubation, respectively; images $(\mathrm{j}),(\mathrm{k})$ and $(\mathrm{l})$ represent the HaCaT cells on $15 \mathrm{CA}-\mathrm{g}$-P(3HB)-EC composite after 1, 3 and 5 days of incubation, respectively and images (m), (n) and (o) represent the HaCaT cells on 20CA- $g$-P(3HB)-EC composite after 1, 3 and 5 days of incubation, respectively. All images were taken at 100× magnification. 


\section{References}

[1] Satyanarayana K. G., Arizaga G. G. C., Wypych F.: Biodegradable composites based on lignocellulosic fibers - An overview. Progress in Polymer Science, 34, 9821021 (2009).

DOI: $10.1016 /$ j.progpolymsci.2008.12.002

[2] Iqbal H. M. N., Kyazze G., Tron T., Keshavarz T.: A preliminary study on the development and characterisation of enzymatically grafted $\mathrm{P}(3 \mathrm{HB})$-ethyl cellulose based novel composites. Cellulose, 21, 3613-3621 (2014).

DOI: $10.1007 / \mathrm{s} 10570-014-0337-9$

[3] Iqbal H. M. N., Kyazze G., Tron T., Keshavarz T.: Laccase-assisted approach to graft multifunctional materials of interest: Keratin-EC based novel composites and their characterisation. Macromolecular Materials and Engineering, in press (2015).

DOI: $10.1002 /$ mame.201500003

[4] Iqbal H. M. N., Kyazze G., Tron T., Keshavarz T.: Laccase-assisted grafting of poly(3-hydroxybutyrate) onto the bacterial cellulose as backbone polymer: Development and characterisation. Carbohydrate Polymers, 113, 131-137 (2014).

DOI: $10.1016 /$ j.carbpol.2014.07.003

[5] Fillat A., Gallardo O., Vidal T., Pastor F. I. J., Díaz P., Roncero M. B.: Enzymatic grafting of natural phenols to flax fibres: Development of antimicrobial properties. Carbohydrate Polymers, 87, 146-152 (2012).

DOI: $10.1016 /$ j.carbpol.2011.07.030

[6] Chang K. C., Chuang T. L., Ji W. F., Chang C. H., Peng Y. Y., Shih H., Hsu L. C., Yeh J. M., Tang W. C., Su Y. C.: UV-curable nanocasting technique to prepare bioinspired superhydrophobic organic-inorganic composite anticorrosion coatings. Express Polymer Letters, 9, 143-153 (2015).

DOI: $10.3144 /$ expresspolymlett.2015.15

[7] Iqbal H. M. N., Kyazze G., Tron T., Keshavarz T.: 'Onepot' synthesis and characterisation of novel $\mathrm{P}(3 \mathrm{HB})$ ethyl cellulose based graft composites through lipase catalysed esterification. Polymer Chemistry, 5, 7004 7012 (2014).

DOI: $10.1039 / C 4 P Y 00857 \mathrm{~J}$

[8] Maiti S., Khatua B. B.: Polyaniline integrated carbon nanohorn: A superior electrode materials for advanced energy storage. Express Polymer Letters, 8, 895-907 (2014).

DOI: $10.3144 /$ expresspolymlett.2014.91

[9] Aracri E., Fillat A., Colom J. F., Gutiérrez A., del Río J. C., Martínez Á. T., Vidal T.: Enzymatic grafting of simple phenols on flax and sisal pulp fibres using laccases. Bioresource Technology, 101, 8211-8216 (2010). DOI: $10.1016 /$ j.biortech.2010.05.080

[10] Cadena E. M., Du X., Gellerstedt G., Li J., Fillat A., García-Ubasart J., Vidal T., Colom J. F.: On hexenuronic acid (HexA) removal and mediator coupling to pulp fiber in the laccase/mediator treatment. Bioresource Technology, 102, 3911-3917 (2011). DOI: $\underline{10.1016 / \mathrm{j} . \text { biortech.2010.11.127 }}$
[11] Elegir G., Kindl A., Sadocco P., Orlandi M.: Development of antimicrobial cellulose packaging through laccase-mediated grafting of phenolic compounds. Enzyme and Microbial Technology, 43, 84-92 (2008).

DOI: $10.1016 /$ j.enzmictec.2007.10.003

[12] Wong K. K. Y., Richardson J. D., Mansfield S. D.: Enzymatic treatment of mechanical pulp fibers for improving papermaking properties. Biotechnology Progress, 16, 1025-1029 (2000).

DOI: $10.1021 / \mathrm{bp} 000064 \mathrm{~d}$

[13] Felby C., Hassingboe J., Lund M.: Pilot-scale production of fiberboards made by laccase oxidized wood fibers: Board properties and evidence for cross-linking of lignin. Enzyme and Microbial Technology, 31, 736741 (2002).

DOI: $10.1016 / \mathrm{S} 0141-0229(02) 00111-4$

[14] Kalemba D., Kunicka A.: Antibacterial and antifungal properties of essential oils. Current Medicinal Chemistry, 10, 813-829 (2003).

DOI: $10.2174 / 0929867033457719$

[15] Yu Q., Wu Z., Chen H.: Dual-function antibacterial surfaces for biomedical applications. Acta Biomaterialia, 16, 1-13 (2015). DOI: $10.1016 /$ j.actbio.2015.01.018

[16] Akaraonye E., Keshavarz T., Roy I.: Production of polyhydroxyalkanoates: the future green materials of choice. Journal of Chemical Technology and Biotechnology, 85, 732-743 (2010).

DOI: $10.1002 /$ jetb. 2392

[17] Rai R., Yunos D. M., Boccaccini A. R., Knowles J. C., Barker I. A., Howdle S. M., Tredwell G. D., Keshavarz T., Roy I.: Poly-3-hydroxyoctanoate $\mathrm{P}(3 \mathrm{HO})$, a medium chain length polyhydroxyalkanoate homopolymer from Pseudomonas mendocina. Biomacromolecules, 12, 2126-2136 (2011).

DOI: $10.1021 / \mathrm{bm} 2001999$

[18] Wattanakornsiri A., Pachana K., Kaewpirom S., Traina M., Migliaresi C.: Preparation and properties of green composites based on tapioca starch and differently recycled paper cellulose fibers. Journal of Polymers and the Environment, 20, 801-809 (2012).

DOI: $10.1007 / \mathrm{s} 10924-012-0494-6$

[19] Shahidi S., Rashidi A., Ghoranneviss M., Anvari A., Rahimi M. K., Bameni Moghaddam M., Wiener J.: Investigation of metal absorption and antibacterial activity on cotton fabric modified by low temperature plasma. Cellulose, 17, 627-634 (2010).

DOI: $10.1007 / \mathrm{s} 10570-010-9400-3$

[20] Shahidi S., Aslan N., Ghoranneviss M., Korachi M.: Effect of thymol on the antibacterial efficiency of plasma-treated cotton fabric. Cellulose, 21, 1933-1943 (2014).

DOI: $10.1007 / \mathrm{s} 10570-014-0250-2$

[21] Rukmani A., Sundrarajan M.: Inclusion of antibacterial agent thymol on $\beta$-cyclodextrin-grafted organic cotton. Journal of Industrial Textiles, 42, 132-144 (2012). DOI: $10.1177 / 1528083711430244$ 
[22] Aggour Y. A.: Reaction kinetics of graft copolymerization and thermochemical studies of the degradation of poly(vinyl alcohol) graft copolymer. Polymer International, 50, 347-353 (2001).

DOI: $10.1002 /$ pi.635

[23] Constantin M., Mihalcea I., Oanea I., Harabagiu V., Fundueanu G.: Studies on graft copolymerization of 3acrylamidopropyl trimethylammonium chloride on pullulan. Carbohydrate Polymers, 84, 926-932 (2011). DOI: $10.1016 /$ j.carbpol.2010.12.043

[24] Sun T., Xu P., Liu Q., Xue J., Xie W.: Graft copolymerization of methacrylic acid onto carboxymethyl chitosan. European Polymer Journal, 39, 189-192 (2003). DOI: 10.1016/S0014-3057(02)00174-X

[25] Li S-M., Jia N., Ma M-G., Zhang Z., Liu Q-H., Sun RC.: Cellulose-silver nanocomposites: Microwaveassisted synthesis, characterization, their thermal stability, and antimicrobial property. Carbohydrate Polymers, 86, 441-447 (2011).

DOI: $10.1016 /$ j.carbpol.2011.04.060
[26] Dong C., Ye Y., Qian L., Zhao G., He B., Xiao H.: Antibacterial modification of cellulose fibers by grafting $\beta$ cyclodextrin and inclusion with ciprofloxacin. Cellulose, 21, 1921-1932 (2014). DOI: $10.1007 / \mathrm{s} 10570-014-0249-8$

[27] Vieira A. C., Vieira J. C., Ferra J. M., Magalhães F. D., Guedes R. M., Marques A. T.: Mechanical study of PLA-PCL fibers during in vitro degradation. Journal of the Mechanical Behavior of Biomedical Materials, 4, 451-460 (2011).

DOI: $10.1016 /$ j.jmbbm.2010.12.006

[28] Tham W. L., Ishak Z. M., Chow W. S.: Water absorption and hygrothermal aging behaviors of sebs-g-mah toughened poly(lactic acid)/halloysite nanocomposites. Polymer-Plastics Technology and Engineering, 53, 472-480 (2014).

DOI: $10.1080 / 03602559.2013 .845208$

[29] Alam A. K. M. M., Beg M. D. H., Mina M. F., Mamun A. A., Bledzki A. K.: Degradation and stability of green composites fabricated from oil palm empty fruit bunch fiber and polylactic acid: Effect of fiber length. Journal of Composite Materials, in press (2014). DOI: $10.1177 / 0021998314560219$ 